\title{
A Comprehensive Review of Sarcoidosis Treatment for Pulmonologists
}

\author{
Andrea S. Melani (1) - Caterina Bigliazzi - Flora Anna Cimmino • \\ Laura Bergantini $\cdot$ Elena Bargagli
}

Received: February 28, 2021 / Accepted: May 17, 2021 / Published online: June 18, 2021

(c) The Author(s) 2021

\section{ABSTRACT}

Due to frequent lung involvement, the pulmonologist is often the reference physician for management of sarcoidosis, a systemic granulomatous disease with a heterogeneous course. Treatment of sarcoidosis raises some issues. The first challenge is to select patients who are likely to benefit from treatment, as sarcoidosis may be

A. S. Melani $(\bowtie) \cdot$ C. Bigliazzi · F. A. Cimmino Pneumology Unit, UOS Pneumologia/UTIP, Dip. Scienze Mediche, Chirurgiche e Neuroscienze, Policlinico Le Scotte, Azienda Ospedaliera Senese, Viale Bracci, 53100 Siena, Italy

e-mail: a.melani@ao-siena.toscana.it

C. Bigliazzi

e-mail: c.bigliazzi@ao-siena.toscana.it

F. A. Cimmino

e-mail: f.cimmino@ao-siena.toscana.it

L. Bergantini

UOC Malattie Respiratorie, Dip. Scienze Mediche, Chirurgiche e Neuroscienze, Università di Siena Policlinico "Le Scotte", Siena, Italy

e-mail: laurabergantini@gmail.com

E. Bargagli

UOC Malattie Respiratorie, Immunology, Allergy, Rare Respiratory Diseases and Lung Transplant Laboratory, Dip. Scienze Mediche, Chirurgiche e Neuroscienze, Università di Siena Policlinico "Le Scotte", Siena, Italy

e-mail: bargagli2@gmail.com self-limiting and remit spontaneously, in which case treatment can be postponed and possibly avoided without any significant impact on quality of life, organ damage or prognosis. Systemic glucocorticosteroids (GCs) are the drug of first choice for sarcoidosis. When GCs are started, there is a $>50 \%$ chance of long-term treatment. Prolonged use of prednisone at $>10 \mathrm{mg}$ /day or equivalent is often associated with severe side effects. In these and refractory cases, steroid-sparing options are advised. Antimetabolites, such as methotrexate, are the second-choice therapy. Biologics, such as antiTNF and especially infliximab, are third-choice drugs. The three treatments can be used concomitantly. Regardless of whether treatment is started, the clinician needs to organize regular follow-up to monitor remissions, flares, progression, complications, toxicity and relapses in order to promptly adjust the drugs used.

Keywords: Sarcoidosis;

Treatment;

Corticosteroids; Methotrexate; Azathioprine; Infliximab; Adalimumab; Anti-TNF 


\section{Key Summary Points}

As sarcoidosis may be self-limiting and remit spontaneously, a first challenge in its management is to decide whether pharmacological treatment can be postponed and possibly avoided without any significant impact on quality of life, organ damage or prognosis.

Systemic glucocorticosteroids are the drug of first choice in the treatment of sarcoidosis. Once started, there is a $>50 \%$ chance of long-term treatment. Prolonged use of prednisone at $>10 \mathrm{mg} /$ day or equivalent is not advised due to frequent severe side effects.

Antimetabolites and biologics are useful additions to corticosteroids in refractory sarcoidosis or as steroid-sparing options. Methotrexate is the most commonly used antimetabolite. Infliximab is the biologic most commonly used in sarcoidosis management.

Eye, nervous system and heart involvement in sarcoidosis may have major clinical consequences and require prompt aggressive management. Other common effects of sarcoidosis, such as fatigue and small fibre neuropathy, may not respond well to conventional sarcoidosis treatments.

Comorbidities are common in sarcoidosis and, except for osteoporosis, are usually treated as in the general population.

Irrespective of treatment, the clinician needs to organize regular follow-ups to monitor remissions, flares, progression, complications, toxicity and relapses in order to promptly adjust treatment.

\section{DIGITAL FEATURES}

This article is published with digital features, including a summary slide, to facilitate understanding of the article. To view digital features for this article go to https://doi.org/10.6084/ m9.figshare.14602299.

\section{INTRODUCTION}

Sarcoidosis is a systemic inflammatory granulomatous disease mainly affecting the lungs and thoracic lymph nodes. In a previous article in this journal, we reviewed emerging aspects of diagnosis and monitoring of the disease. This narrative paper aims to review and update sarcoidosis management. Our search is based on results from studies on sarcoidosis found in PubMed analysis. We searched MEDLINE electronic databases up to 31 December 2020 via PubMed, using a combination of the terms "sarcoidosis" [MeSH] OR "sarcoid" *[tiab] AND "Anti-Inflammatory Agents" [MeSH] AND (english[la]) up to 31 December 2020. We obtained more than 2538 hits. Abstracts were reviewed and bibliographies of relevant papers were searched and examined. The papers selected were hand-searched for additional works on the topic. The present review does not contain any new studies with human participants or animals performed by any of the authors.

\section{Choice of Treatment}

Once the diagnostic work-up of sarcoidosis is completed, the physician has to decide whether treatment is necessary, balancing the trade-offs between pros and cons. Sarcoidosis may have a self-limiting course without any negative impact on quality of life or prognosis, whereas prolonged use of systemic glucocorticoids (GCs), the pharmacological treatment of first choice, is often associated with significant toxicity and impaired quality of life [1]. The indications for systemic treatment in sarcoidosis are shown in Table 1. Key criteria at the start of treatment are the burden of symptoms and the degree of organ damage. In a UK registry, more 
Table 1 Indications for systemic treatment in sarcoidosis

Symptoms impairing quality of life

Persistent lung infiltrates/decline in lung function at follow-up

Cardiac sarcoidosis

Neurological sarcoidosis

Ocular sarcoidosis not responding to topical therapy

Hypercalcaemia and/or hypercalciuria resistant to dietary vitamin $\mathrm{D}$ and calcium restrictions

Severe skin involvement with disfiguration (e.g. lupus pernio)

Other end organ failure

than a third of patients with sarcoidosis did not receive any systemic pharmacological treatment at diagnosis [2].

\section{TOPICAL TREATMENT \\ IN THE MANAGEMENT OF SARCOIDOSIS}

Topical therapy may be effective in managing sarcoidosis. Topical GCs are the local treatment of first choice in many cases of skin, joint and eye sarcoidosis. Less evidence is available about the effectiveness of inhaled corticosteroids in pulmonary sarcoidosis. One study found that inhaled budesonide $1.2-2 \mathrm{mg} /$ day did not ensure any useful result [3]. Another study observed that inhaled budesonide $0.8 \mathrm{mg}$ twice a day may help maintain improvement previously achieved with GCs [4]. Two other studies found that inhaled fluticasone $0.8-1.0 \mathrm{mg}$ twice a day was not effective for GC-sparing in acute [5] and chronic pulmonary sarcoidosis [6], although it could reduce coughing. Overall, these results suggest that inhaled GCs cannot be routinely recommended in pulmonary sarcoidosis, but may be useful if coughing and airway hyperreactivity are the predominant (not severe) symptoms. In the British Thoracic Society sarcoidosis registry, $8 \%$ of patients were receiving inhaled GCs [2].

\section{ROLE OF SYSTEMIC GLUCOCORTICOSTEROIDS (GCS) IN MANAGING SARCOIDOSIS}

GCs are the drug of first choice when systemic treatment is required (see Table 2 for main side effects and suggested monitoring) [1, 7]. Although few randomized studies have shown the benefits of GCs $[8,9]$, case series have documented their effectiveness since 1951 [10]. GCs do not give better outcomes than placebo in asymptomatic sarcoidosis without evidence of lung disease, but may be useful in patients with pulmonary infiltrates, although it is not certain whether they can prevent fibrosis [9]. Most experts recommend oral prednisone $20-40 \mathrm{mg}$ daily or equivalent in a single administration for treatment of naïve sarcoidosis patients [11]. A British Thoracic Society Clinical Statement recommends a GC dose from $10 \mathrm{mg}$ of prednisolone per day in long-standing, slowly progressive sarcoidosis [12]. Higher doses ( $1 \mathrm{mg} / \mathrm{kg} /$ day or $500-1000 \mathrm{mg} /$ day methylprednisolone i.v. in a hospital setting for 3 days) are sometimes attempted to obtain rapid remission in cases of life-threatening onset of sarcoidosis [11]. Once treatment is started, it is usually continued for several months. Before starting therapy, the patient must receive clear information about the details of treatment, including possible adverse effects of the drugs. The induction dose is usually maintained for at least 6-8 weeks. When there is no clinical improvement after 12 weeks of treatment, a response to longer courses is unlikely. In cases of remission, the dose of prednisone should be gradually reduced to as low as possible (10 $\mathrm{mg} /$ day), usually with a decrement every 4 weeks. Once a daily dose of $10 \mathrm{mg}$ prednisone is reached, most clinicians maintain this dose for 3-6 months before lowering it again. GCs may sometimes be tapered to complete discontinuation. The probability of relapse after suspending GCs ranges from 14 to $74 \%$ for acute disease and about $75 \%$ for chronic forms. Approximately half of all relapses occur 2-6 months after suspension and most within 12 months [11, 13]. For patients who relapse while off GCs, reintroduction of $20 \mathrm{mg} /$ day prednisone for a 
Table 2 Main drugs used in sarcoidosis

\begin{tabular}{|c|c|c|}
\hline Drug & Main adverse effects & Baseline and monitoring examinations \\
\hline Glucocorticoid & $\begin{array}{l}\text { Weight gain, fluid retention, osteoporosis, } \\
\text { hyperglycaemia, hypertension, gastritis, muscle } \\
\text { weakness, opportunistic infections, psychosis, } \\
\text { mood swings, insomnia, thrush, cataract, } \\
\text { glaucoma, osteonecrosis of femoral head }\end{array}$ & $\begin{array}{l}\text { Weight, blood pressure, serum lipids and glucose } \\
\text { at baseline and every } 3 \text { months, bone mineral } \\
\text { density and ophthalmologic examination } \\
\text { yearly }\end{array}$ \\
\hline Methotrexate & $\begin{array}{l}\text { Dyspepsia, mucositis, liver and bone marrow } \\
\text { toxicity, fatigue, alopecia, increased risk of } \\
\text { infections including opportunists, } \\
\text { hypersensitivity pneumonia }\end{array}$ & $\begin{array}{l}\text { Blood, liver and renal indices at baseline and at } \\
\text { every } 2-4 \text { weeks for the first } 3 \text { months, every } \\
2-3 \text { months thereafter; contraindicated in } \\
\text { patients with underlying liver disease and } \\
\text { chronic viral hepatitis }\end{array}$ \\
\hline Azathioprine & $\begin{array}{l}\text { As for MTX and also jaundice, myalgia, blurred } \\
\text { vision }\end{array}$ & As for MTX \\
\hline Leflunomide* & $\begin{array}{l}\text { As for MTX and also diarrhoea, skin rash, } \\
\text { peripheral neuropathy, alopecia, systemic } \\
\text { hypertension }\end{array}$ & As for MTX \\
\hline Mycophenolate & $\begin{array}{l}\text { Diarrhoea, nausea, vomiting, leukopenia, } \\
\text { anaemia, cytomegalovirus viraemia, infections, } \\
\text { hyperglycaemia, hepatitis }\end{array}$ & $\begin{array}{l}\text { As for MTX; it may cause increase in blood } \\
\text { concentrations of creatinine }\end{array}$ \\
\hline Cyclophosphamide & $\begin{array}{l}\text { As for MTX and also haemorrhagic cystitis, } \\
\text { cytopenia }\end{array}$ & As for MTX. Urinalysis every month \\
\hline Hydroxychloroquine & $\begin{array}{l}\text { Rash, neuromyopathy, retinopathy; } \\
\text { cardiomyopathy, gastrointestinal intolerance, } \\
\text { skin pigmentation }\end{array}$ & $\begin{array}{l}\text { Eye examination at baseline and then every } \\
6-12 \text { months }\end{array}$ \\
\hline $\begin{array}{l}\text { Infliximab and } \\
\text { adalimumab }\end{array}$ & $\begin{array}{l}\text { Allergic local reactions, skin rashes, } \\
\text { demyelinating disease, lupus-like syndrome, } \\
\text { congestive heart failure, thromboembolic } \\
\text { disease, increased risk of reactivation of latent } \\
\text { infections including tuberculosis }\end{array}$ & $\begin{array}{l}\text { As for MTX; close monitoring during injection, } \\
\text { dermatological evaluation at baseline. } \\
\text { Contraindicated in cases of severe congestive } \\
\text { heart failure }\end{array}$ \\
\hline Rituximab & $\begin{array}{l}\text { Reactivation of hepatitis, progressive multifocal } \\
\text { leukoencephalopathy, headache, muscle } \\
\text { spasms, pancytopenia, fatigue }\end{array}$ & $\begin{array}{l}\text { Serum immunoglobulins every } 3-6 \text { months, } \\
\text { blood chemistry every } 1-3 \text { months } \\
\text { Contraindicated in cases of severe congestive } \\
\text { heart failure. Overall, there is less probability of } \\
\text { immune response to various vaccines }\end{array}$ \\
\hline
\end{tabular}

MTX methotrexate

*Some authors suggest an initial dose of $80-160 \mathrm{mg}$ and then $80 \mathrm{mg}$ every other week

median of 3 weeks usually ensures a new remission [13]. Many patients require long-term GC treatment. The toxicity of long-term GC treatment is substantial, and weight gain is the most frequent side effect; the risk of side effects depends on the cumulative dose and the 


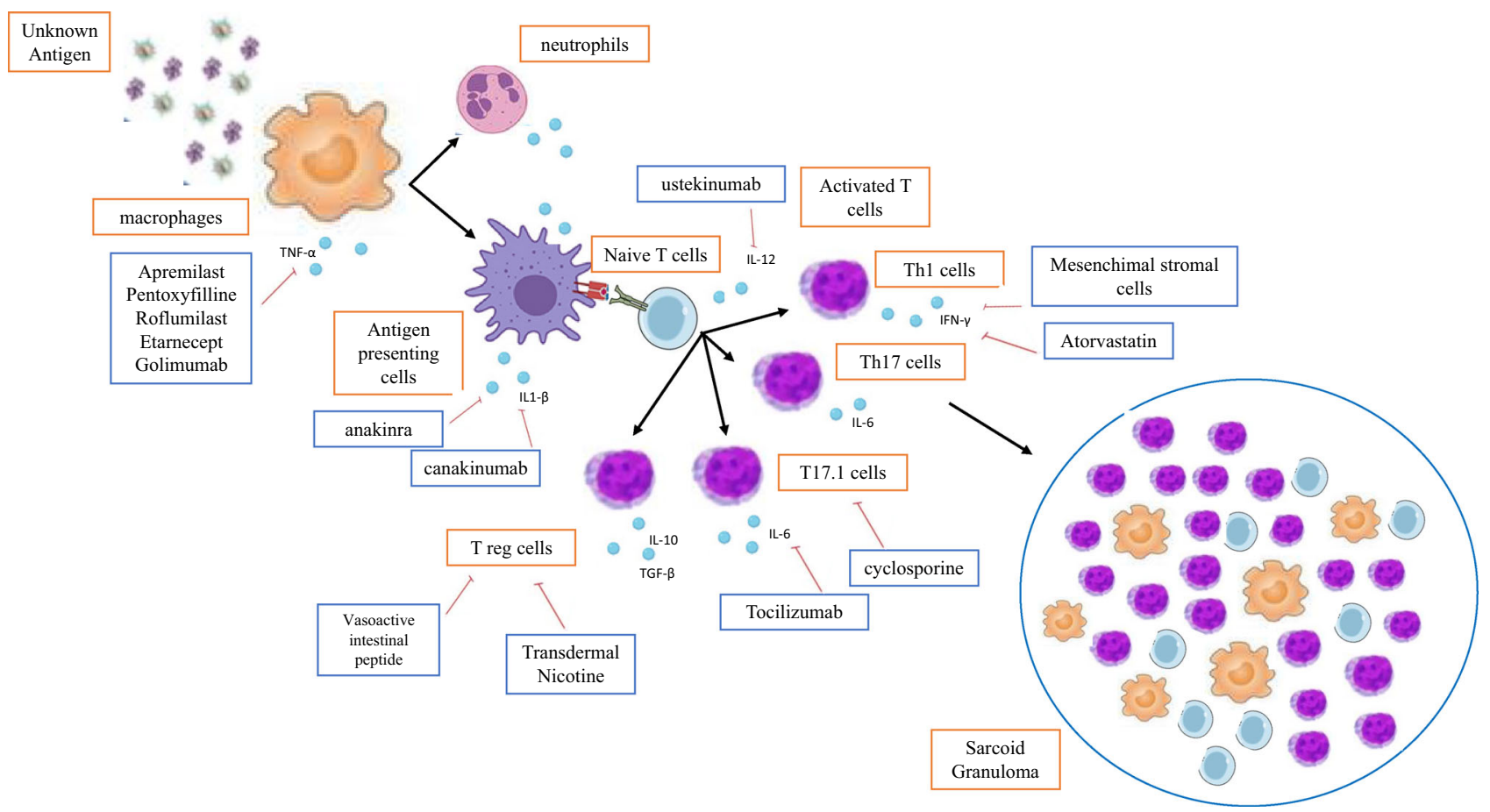

Fig. 1 Schematic depicting mechanisms of sarcoidosis pathegenesis and treatment. Drugs against specific pathogenic steps are displayed in blue boxes and arrows

duration of treatment $[1,7,14]$. Patients who do not respond to GCs, those who cannot be controlled over the long term with $<10 \mathrm{mg}$ /day prednisone, or those who develop intolerance to GC are candidates for treatment with alternative drugs (Fig. 1) [15].

\section{ROLE OF ANTIMETABOLITES IN MANAGING SARCOIDOSIS}

Antimetabolite immunosuppressants are the first addition (or alternative) to GC treatment. Some characteristics of these drugs are shown in Table 2 [7, 15-19]. Note that tapering the dose of GCs is not recommended for at least 2-3 months after the addition of an antimetabolite, as the latter takes several weeks to reach maximum therapeutic effect. Some clinics start the antimetabolite and GCs together in patients with severe forms of sarcoidosis, such as cardiac sarcoidosis, neurological sarcoidosis and posterior uveitis. Antimetabolites are contraindicated during active infections, pregnancy and in breast-feeding women, as they cross the placenta. Live vaccinations are not advised during immunosuppressant treatment. A yearly influenza vaccination is recommended along with pneumonia vaccine at baseline and every 5 years [19]. Baseline serology for HIV, hepatitis $B$ and $C$, and the interferon-gamma release assay (IGRA) test for tuberculosis is recommended, and positive cases should be referred to a specialist.

Methotrexate (MTX) is the additional (or alternative) drug of first choice with respect to GCs [15-18, 20, 21]. When MTX is added to GCs in cases of refractory sarcoidosis, at least one third of all patients may still not respond. MTX mainly inhibits adenosine deaminase, increasing adenosine levels, with several interactions and consequences for the immune system. It may be administered orally with variable uptake. Doses are usually given weekly to limit toxicity. The starting dose of MTX is often $5 \mathrm{mg} /$ week s.c. or i.m., with gradual $2.5 \mathrm{mg}$ increments every 2 weeks up to a dose of $15 \mathrm{mg} /$ week or higher, if tolerated and necessary [20]. 
Rheumatology guidelines permit the use of MTX up to $25 \mathrm{mg} /$ week [18]. Combination with oral folic acid at $1-2 \mathrm{mg} /$ day reduces the toxicity but not anti-inflammatory effects, and is recommended [20]. As MTX is excreted by the kidneys, it is contraindicated in patients with advanced chronic kidney disease (glomerular filtration rate $<30-50 \mathrm{ml} / \mathrm{min}$ ). Penicillin, probenecid, proton-pump inhibitors and valproate can increase plasma concentrations of MTX, while trimethoprim may predispose to additive hepatotoxicity and blood toxicity. By contrast, concomitant use of neomycin and paromomycin have been found to reduce gastrointestinal absorption of MTX. Side effects lead to discontinuation of MTX in approximately 20\% of users. The most common adverse events are gastrointestinal (more frequent in younger patients) and may sometimes be attenuated by splitting the dose, taking tablets during a meal or switching to parenteral administration. At periodic checks, approximately $25 \%$ of patients on MTX showed serum transaminase levels more than three times the upper limit of normal during the first year; liver toxicity may respond to dose reduction [21] and warrants referral to a liver specialist. Avoidance of alcohol intake is suggested during MTX treatment. About $4 \%$ of users discontinue MTX due to excessive liver toxicity. Approximately $10 \%$ of patients with rheumatological diseases on MTX monotherapy experience neutropenia, severe in $0.4 \%$ of cases [22]. Another serious though uncommon complication is hypersensitivity pneumonia; the risk is dose-dependent and usually occurs after months to years of MTX treatment. MTX should be discontinued at least 2-3 months prior to any planned pregnancy; otherwise women of reproductive age should practise effective birth control [17]. The effect of MTX on male fertility is unclear [23].

Azathioprine (AZA) is the prodrug of 6-mercaptopurine that halts the purine pathway and proliferating cells. The oral starting dose of AZA is usually $50 \mathrm{mg} / \mathrm{day}$, with $25 \mathrm{mg}$ increments every 2 weeks to a maximum of 150-$200 \mathrm{mg} /$ day. About $20 \%$ of users report gastrointestinal side effects; AZA may also cause pancreatitis, often not dose-related [14, 18]. Thiopurine S-methyltransferase (TPMT) and
Nudix hydrolase 15 (NUDT15) mutations are reported to be responsible for poor metabolization of AZA. TPMT and NUDT15 genotyping and phenotyping are recommended for AZA users. Life-threatening bone marrow toxicity is mostly observed in carriers of homozygous TPMT mutations, while heterozygous mutations (occurring in $11 \%$ of the population) are often associated with intermediate enzyme levels and require a lower than standard dosage [24]. Co-administration of drugs that influence TPMT or xanthine oxidase activity, such as allopurinol and febuxostat, can increase AZA toxicity. In a retrospective unblinded uncontrolled cohort study, AZA and MTX showed similar outcomes but AZA use was associated with twice the risk of infections [25]; however, the definition of infection was not identical between treatment groups. Unlike MTX and leflunomide, which are excreted by the kidneys, AZA may be relatively safe in patients with renal failure (excluding stage 3 or higher chronic kidney failure). AZA is a particularly useful alternative to MTX in patients who have chronic liver toxicity at baseline. An increased risk of lymphoma has been reported in patients using a combination of anti-TNF- $\alpha$ and AZA [18]. AZA is probably the safest second-line drug for couples planning a pregnancy [17].

Leflunomide (LEF) inhibits mitochondrial dihydroorotate dehydrogenase, blocking expansion of activated $\mathrm{T}$ lymphocytes. The typical oral starting dose is $10 \mathrm{mg} /$ day or every other day, which can be increased after a few weeks to $20-30 \mathrm{mg} /$ day if well tolerated. Two retrospective cohort studies on 108 patients supported the use of LEF, alone but usually in combination with MTX, in sarcoidosis patients [26]. The action of LEF is similar to that of MTX, but their toxicity profiles are different. LEF is usually associated with less nausea than MTX, but a proportion of patients interrupt treatment due to diarrhoea and/or liver damage. Silent liver fibrosis has been reported in patients on MTX and LEF. Although uncommon, LEF can cause peripheral neuropathy, and some authors therefore suggest caution in prescribing it for patients with diabetes or the elderly. As LEF has a prolonged half-life of more than 30 days, in patients who develop severe toxicity, 
cholestyramine treatment should be considered to enhance withdrawal of the drug and earlier remission of adverse events [15].

Mycophenolate mofetil (MMF) is the prodrug of the mycophenolic acid it is well absorbed when administered orally and is activated by plasma esterases. MPA blocks guanine nucleotide production, inhibiting lymphocyte proliferation, and is without significant myelotoxicity. As it is eliminated by the kidneys, the dose should be adjusted in patients with renal failure $(<30 \mathrm{ml} / \mathrm{min})$ [27]. The usual oral starting dose is $500 \mathrm{mg}$ twice a day, which can be increased by $250 \mathrm{mg}$ every few weeks to a maximum dose of $1500 \mathrm{mg}$ twice daily. The most common side effects are gastrointestinal; dividing the daily dose into more than two doses may help to control mild symptoms [15]. A retrospective single-centre study of 37 sarcoidosis patients did not find any significant improvement in lung function tests associated with MMF, whereas a good response was reported in ocular and neurosarcoidosis patients [28]. MMF is therefore used mainly to treat extrapulmonary sarcoidosis.

Cyclophosphamide is cytotoxic to resting and dividing lymphocytes and is therefore usually administered intravenously at $500-1000 \mathrm{mg} /$ week or every other week as a short-term rescue option in very severe acute forms of sarcoidosis, not controlled by MTX or AZA [15].

Chloroquine (CQ) and the relatively less toxic derivative hydroxychloroquine (HCQ), known antimalarial drugs, prevent the acidification of lysosomal enzymes necessary for antigen presentation and toll-like receptor 2 activation. They may also inhibit the conversion of 25-(OH)vitamin D to 1,25-(OH)vitamin $\mathrm{D}$, suppressing sarcoidosis-associated hypercalcaemia and hypercalciuria. CQ and HCQ have large-volume tissue distribution, long half-life and renal excretion. Concurrent use may increase levels of digoxin and metoprolol, as they are substrates for cytochrome P450. HCQ may reduce absorption of MTX, while concomitant use of proton-pump inhibitors may reduce absorption of HCQ [29]. These orally administered drugs are used for patients with skin sarcoidosis, hypercalcaemia [11] or myalgia
[30], although the drugs themselves can sustain muscular pain as a side effect. Fewer results are available for cases of lung sarcoidosis. A randomized placebo-controlled study of 18 pulmonary sarcoidosis patients, initially treated for 6 months with CQ $750 \mathrm{mg} /$ day, tapering every 2 months to $250 \mathrm{mg}$, reported a significant improvement in symptoms and lung function, but relapses were observed after the drug was discontinued [31]. Unlike immunosuppressant drugs, CQ and HCQ are not associated with increased risk of infectious complications. The most common adverse effects are gastrointestinal, but the main concern is the risk of irreversible retinopathy, which increases with cumulative dose and is a contraindication for long-term treatment [29]. The risk of retinal toxicity increases with doses over $5 \mathrm{mg} / \mathrm{kg}$ body weight/day, cumulative doses greater than 600-1000 g, stage 3-5 chronic kidney diseases and co-medication with tamoxifen for more than 6 months [32]. CQ and HCQ are considered safe for use in pregnant and breast-feeding women [17].

\section{ROLE OF ANTIMETABOLITES IN THE MANAGEMENT OF SARCOIDOSIS}

Biologics have gained a place as third-line therapy in sarcoidosis patients who do not benefit fully from GCs and antimetabolites, or if these drugs prove too toxic. This patient subset is about $5-15 \%$ of those seen in tertiary sarcoidosis centres [33]. Anti-TNF- $\alpha$ agents are the biologic of first choice. The main indications for anti-TNF- $\alpha$ treatment in sarcoidosis are reported in Table 3 [33]. Anti-TNF- $\alpha$ agents are usually effective, and no more than $10 \%$ of drug discontinuations are due to lack of effectiveness [33-35]. The risk of intolerance and infections, including reactivation of latent tuberculosis, is relatively high, mainly with regard to infliximab (IFX), the most effective biologic for sarcoidosis. Paradoxically, reports of sarcoid-like reactions may occur in patients treated with anti-TNF- $\alpha$ agents for diseases other than sarcoidosis [33]. 
Among anti-TNF- $\alpha$ agents, intravenous IFX is the drug of first choice in sarcoidosis. In a 24-week randomized double-blind controlled trial with 138 chronic pulmonary sarcoidosis patients (almost all already on GCs and antimetabolites), IFX obtained a significant increase in predicted forced vital capacity (FVC) $\%$ over placebo $(+2.4 \%$, primary outcome), but not in St. George's Respiratory Questionnaire (SGRQ), 6-minute walking distance (6MWD) or post-exertional Borg dyspnea score; discontinuation due to side effects was about 5\% [36]. In this seminal study, there was no difference in the response rate to IFX for 3 versus $5 \mathrm{mg} / \mathrm{kg}$ of ideal body weight [36], but $5 \mathrm{mg} / \mathrm{kg}$ is usually preferred as induction regimen. Loading doses are typically given at weeks 0,2 and 6 ; then the frequency of maintenance infusions is every $4-8$ weeks, increasing to every week if the patient fails to respond. It is thought that patients with more severe disease obtain greater benefits [12]. In the only other randomized trial of IFX to date, there was no significant difference in response between those receiving IFX or placebo, but treatment was only studied for 6 weeks, possibly too short a period to observe results, and the study population numbered only 13 , possibly too small a sample size [37]. A large retrospective study

Table 3 Main indications for anti-TNF- $\alpha$ therapy in sarcoidosis

Active disease for more than 1 year refractory to firstand second-choice treatments

Forced vital capacity $<55 \%$

Moderate to severe dyspnea

Diffuse reticular-nodular lung infiltrates

High baseline lung inflammation measured by positron emission tomography

Elevated serum levels of C-reactive protein

Chronic uveitis

Lupus pernio

Severe neurological involvement from France suggests that anti-TNF treatment may give more benefits in extrapulmonary (28 cardiac, 44 skin and 63 neuro) sarcoidosis than in pulmonary forms. Adverse events were observed in about half of users and led to discontinuation of treatment in almost a quarter of the population [34]. One study showed that TNF- $\alpha$ Gly308Ala polymorphisms were predictive of response to IFX therapy [38]. As discontinuation of treatment is associated with at least a $50 \%$ chance of relapse, many patients are treated for years. A gradual withdrawal of the drug by extending the interval between doses has been suggested [33].

As IFX is a chimeric monoclonal antibody comprising mouse proteins, chronic use may induce autoantibodies that reduce drug efficacy. Allergic reactions are possible (usually $<5 \%$ of total), although they are seldom severe. Stopping and restarting IFX treatment is thought to predispose to autoantibody production and allergic reactions. Concurrent use of other immunosuppressants is believed to reduce the risk of autoantibody generation and does not seem to increase the risk of adverse effects or infections. Likewise, concomitant use of IFX and a higher daily dose of prednisone $15 \mathrm{mg}$ or equivalent is contraindicated, as it may block anti-TNF therapies.

Biosimilars are biologics that do not significantly differ in safety and efficacy from the reference product, but are cheaper. Clinicians are advised against switching patients currently treated with the IFX reference product to biosimilars [33]. However, an IFX biosimilar has been shown to be effective in sarcoidosis patients [39], so it is thought that treatment of naïve patients can start with IFX generics.

Adalimumab (ADA) is a fully human antiTNF- $\alpha$ monoclonal antibody, usually used in patients intolerant to IFX [40] and in cases of ocular sarcoidosis (see Ocular sarcoidosis section). Although the composition of ADA is fully human, almost $20 \%$ of a large European series treated with ADA developed autoantibodies [41]. The risk of allergic reactions to ADA is not insignificant [33]. Another advantage over IFX is that subcutaneous administration makes selfadministration possible. ADA is usually administered subcutaneously at a dose of $40 \mathrm{mg}$ every 
2 weeks, prolonging the scheduled timing when response is good and increasing to once a week in the absence of response. ADA does not elicit as robust a response as IFX, usually takes longer to show its benefits and is associated with a lower remission rate when discontinued [33].

Rituximab is a chimeric monoclonal antibody against $\mathrm{CD} 20+$ cells. It leads to B-cell depletion lasting up to 6 months after administration. In a prospective observational study, rituximab did not have any statistically significant effect, but it improved FVC in 5 out of 10 patients [42]. Rituximab has been used effectively in extrapulmonary sarcoidosis. The dose and administration schedule are not fully defined, but $1000 \mathrm{mg}$ is often given intravenously (independent of body weight), repeating 2 weeks later [33]. Rituximab is relatively well tolerated, but infusion-related reactions are common (30\% with the first infusion), and premedication with paracetamol and corticosteroids (usually $100 \mathrm{mg}$ hydrocortisone) are usually advocated. It has a lower response rate and a longer response time than anti-TNF- $\alpha$ and is unlikely to be associated with autoantibody production. Because it suppresses immunoglobulin production, there is an overall increased risk of (mainly viral) infections. Rituximab has been shown to reactivate herpes simplex virus and herpes zoster virus, while immunoglobulin replacement therapy can be effective in reducing risk of infections in patients on prolonged rituximab therapy, but there are currently no guidelines regarding timing and indications [33].

The beneficial effects of adrenocorticotropic hormone $(\mathrm{ACTH})$ in sarcoidosis have been known for many years, as it was initially approved by the Food Drug Administration (FDA) for the treatment of sarcoidosis in 1952. In a single-blind prospective study, ACTHAR gel, a repository corticotropin injection therapy consisting of a mixture of pituitary extracts enriched with $\mathrm{ACTH}$, at a subcutaneous dose of 80 or $40 \mathrm{IU}$ twice a week offered benefits and GC-sparing effects in 16 patients with chronic pulmonary sarcoidosis who completed 24 weeks of treatment [43]. A Delphi panel recommended that lack of efficacy for ACTHAR gel should be evaluated after 3-6 months of therapy [44].
Beyond antimicrobial function, many antibiotics have immunomodulatory effects. Monotherapy with antimicrobials is not effective for sarcoidosis. However, an 8-week openlabel trial has shown that concomitant use of levofloxacin, ethambutol, azithromycin and rifampin, also known as CLEAR therapy, may improve quality of life and FVC in some pulmonary sarcoidosis patients [45], although CLEAR was generally not well tolerated. A randomized, placebo-controlled, single-masked trial of 30 subjects with chronic symptomatic skin sarcoidosis found an improvement in skin lesions at 180-day follow-up of the group receiving CLEAR for 8 weeks [46]. Another ongoing study is evaluating the efficacy of CLEAR in patients with chronic lung sarcoidosis (NCT02024555). A Japanese study of cardiac sarcoidosis showed good outcomes and safety using the macrolide clarithromycin 200-$400 \mathrm{mg} /$ day with tetracycline doxycycline hydrochloride $100-200 \mathrm{mg} /$ day [47]. Other drugs that are or could be used in the management of sarcoidosis are reported in Table 4 [48-70].

\section{MANAGEMENT OF EYE, NEUROLOGICAL AND CARDIAC SARCOIDOSIS}

Eye, neurological and cardiac involvement are relatively common in sarcoidosis and have important implications for prognosis. They are therefore considered in a separate section.

The course of ocular sarcoidosis is usually unrelated to that of extra-ocular sarcoidosis. Topical GCs are often effective for anterior uveitis, with an administration frequency ranging from once a day to hourly, based on the degree of inflammation. Cycloplegic eye drops are used concomitantly to relieve pain. Periocular or intravitreal GC-depot injections and implants are used to treat panuveitis, posterior uveitis and when frequent use of drops is impracticable. Unfortunately, regional GC treatments are often associated with local adverse effects, such as glaucoma and/or cataract [71]. A few alternatives to topical GCs have been tested: intravitreal MTX and ADA are 
Table 4 Other drugs which are or can be used in the management of sarcoidosis

\begin{tabular}{|c|c|c|c|}
\hline Drug & Main activity & Outcome & References \\
\hline Abatacept & Anti-CTLA-4 & Under investigation for sarcoidosis & {$[48]$} \\
\hline Anakinra & IL-1 receptor antagonist & Under investigation for cardiac sarcoidosis & NCT04017936 \\
\hline Apremilast & $\begin{array}{l}\text { Phosphodiesterase- } 4 \text { inhibitor blocking } \\
\text { TNF- } \alpha \text { release from macrophages }\end{array}$ & Encouraging results in skin sarcoidosis & {$[49]$} \\
\hline Atorvastatin & $\begin{array}{l}\text { Inhibition of IFN- } \gamma \text { production by } \mathrm{T} \\
\text { lymphocytes }\end{array}$ & $\begin{array}{l}\text { No GC-sparing effect in lung sarcoidosis, but } \\
\text { reduction of mild-to-moderate flares }\end{array}$ & {$[50]$} \\
\hline Canakinumab & $\begin{array}{l}\text { Anti-IL-1 } \beta \text {, interfering with innate } \\
\text { immunity }\end{array}$ & Under investigation for lung sarcoidosis & NCT02888080 \\
\hline Cyclosporine & $\begin{array}{l}\text { Calcineurin antagonist, inhibiting } \\
\text { T-lymphocyte function }\end{array}$ & No advantage & {$[51,52]$} \\
\hline Daclizumab & $\begin{array}{l}\text { Blocking CD25, part of the IL-2 } \\
\text { receptor }\end{array}$ & $\begin{array}{l}\text { Encouraging results but reports (although rare) } \\
\text { of cancer }\end{array}$ & {$[53]$} \\
\hline Etanercept & Anti-TNF & No benefits for pulmonary and eye sarcoidosis & {$[54,55]$} \\
\hline Golimumab & Anti-TNF & No advantage & {$[56]$} \\
\hline Lenalidomide & $\begin{array}{l}\text { Inhibition of NF- } \kappa \mathrm{B} \text {, a major } \\
\text { inflammatory signalling family }\end{array}$ & Better tolerated than thalidomide & {$[57]$} \\
\hline Maraviroc & Inhibitor of the chemokine CCR5-r & Under investigation & NCT0213471 \\
\hline $\begin{array}{r}\text { Mesenchymal } \\
\text { stromal cells }\end{array}$ & $\begin{array}{l}\text { Inhibition of } \mathrm{T} \text { lymphocytes by } \\
\text { decreasing IFN- } \gamma \text { activity }\end{array}$ & $\begin{array}{l}\text { GC-sparing effect in patients with advanced } \\
\text { lung sarcoidosis, but with increase in mean } \\
\text { pulmonary artery pressure }\end{array}$ & {$[58]$} \\
\hline $\begin{array}{l}\text { Transdermal } \\
\text { nicotine }\end{array}$ & $\begin{array}{l}\text { Attenuation of M1 polarization and } \\
\text { NF- } \kappa \mathrm{B} \text { activation; activation of Tregs }\end{array}$ & Promising results & [59] \\
\hline Pentoxifylline & $\begin{array}{l}\text { Phosphodiesterase- } 4 \text { inhibitor blocking } \\
\text { TNF- } \alpha \text { release from macrophages }\end{array}$ & $\begin{array}{l}\text { Promising results in lung sarcoidosis but } \\
\text { common gastrointestinal intolerance }\end{array}$ & {$[60]$} \\
\hline Roflumilast & $\begin{array}{l}\text { Phosphodiesterase- } 4 \text { Inhibitor blocking } \\
\text { TNF- } \alpha \text { release from macrophages }\end{array}$ & $\begin{array}{l}\text { Promising reduction of flares in chronic } \\
\text { fibrotic lung sarcoidosis }\end{array}$ & {$[61]$} \\
\hline Thalidomide & $\begin{array}{l}\text { Inhibition of NF- } \kappa \mathrm{B} \text {, a major } \\
\text { inflammatory signalling family }\end{array}$ & $\begin{array}{l}\text { Contrasting results in patients with refractory } \\
\text { lung and skin sarcoidosis but common side } \\
\text { effects }\end{array}$ & [62-64] \\
\hline $\begin{array}{l}\text { Tocilizumab, } \\
\text { sarilumab }\end{array}$ & $\begin{array}{l}\text { Anti-IL-6r antibody, involved in } \\
\text { differentiation of Th17 and Th17.1 } \\
\text { cells }\end{array}$ & Improvement in case series & {$[65]$} \\
\hline $\begin{array}{l}\text { Tofacitinib, } \\
\text { ruxolitinib }\end{array}$ & $\begin{array}{l}\text { Inhibitor of Janus kinase, a major } \\
\text { inflammatory signalling family }\end{array}$ & $\begin{array}{l}\text { Improvement in case series, especially for skin } \\
\text { sarcoidosis }\end{array}$ & [66-69] \\
\hline Ustekinumab & $\begin{array}{l}\text { Blocker of the minor subunit of IL-12, } \\
\text { involved in differentiation of naïve T } \\
\text { cells into Th1 cells }\end{array}$ & No advantage & {$[56]$} \\
\hline
\end{tabular}


Table 4 continued

\begin{tabular}{llll}
\hline Drug & Main activity & Outcome & References \\
\hline $\begin{array}{l}\text { Vasoactive } \\
\text { intestinal } \\
\text { peptide }\end{array}$ & Improvement of Treg function & Promising results & {$[70]$} \\
\hline
\end{tabular}

promising for non-infectious uveitis [71]. A randomized controlled trial comparing regional versus systemic GCs on long-term vision in patients with uveitis (not only of sarcoid origin) found that the latter treatment achieved better outcomes [72]. GC therapy at standard dosage and schedule is usually effective in ocular sarcoidosis [72]. Among GC-sparing drugs, MTX and MMF have been used in ocular sarcoidosis with good results; many ophthalmologists prefer MMF [73, 74]. Anti-TNFs are also effective in patients with refractory uveitis, rituximab being another alternative [71]. In a multicentre French study of patients treated with anti-TNF drugs for refractory uveitis, IFX proved as effective as ADA, but with a non-significantly higher incidence of severe adverse events, mainly skin rashes and fatigue [75]. Two controlled studies with 446 subjects showed efficacy of ADA in adults (about $10 \%$ of whom had sarcoidosis) with active (VISUAL I) and inactive (VISUAL II) non-infectious intermediate or posterior uveitis or panuveitis [76, 77]. ADA has received FDA approval for non-infectious uveitis. Approximately one fifth of patients with ocular sarcoidosis undergo eye surgery, including cataract extraction (17\%), trabeculectomy $(4 \%)$, retinal detachment repair (1\%) and epiretinal membrane peel (1\%). To avoid a severe postoperative inflammatory reaction, surgery should ideally be considered when quiescence of intraocular inflammation has been achieved for at least 3 months. The main causes of irreversible vision loss are glaucoma (usually a complication of ocular sarcoidosis) and chronic maculopathy related to posterior uveitis. When macular oedema persists without active inflammation, intravitreal injections of bevacizumab may be effective [71].

Neurosarcoidosis usually requires treatment because spontaneous remission is uncommon and permanent lesions are frequent. There have been no randomized controlled trials on sarcoid involvement of the central nervous system. Treatment is usually based on expert opinions and case series. GCs at a starting dose of $1 \mathrm{mg} /$ $\mathrm{kg} /$ day are the first-line therapy. Except for facial nerve palsy, which may benefit from only a few weeks of therapy, long-term treatment is the rule, and most patients also receive secondand third-line therapy. MTX is traditionally the first second-line choice, with a response rate of about $60 \%$, as seen in pulmonary sarcoidosis [78]. In comparative studies, MTX has been found to be more rapidly effective and associated with less risk of relapse (but more adverse effects) than MMF [79]. Short-term pulses of cyclophosphamide may be attempted in severe cases to accelerate early response. Case series have reported good results with IFX, which seems to be more effective than cyclophosphamide [80] and is increasingly used [34, 35, 81]; however, infective complications and toxicity are common, and withdrawal of treatment is associated with high rates of relapse [33-35]. Note that the longer the history of neurosarcoidosis before starting IFX, the lower the odds of a favourable treatment response [33]. Many questions remain unsolved regarding maintenance treatment, such as the duration of therapy and the best strategy for tapering. Radiation therapy with 20-25 Gy may be considered a last therapeutic option in patients who do not respond to drugs [78]. Some patients may require neurosurgery at some point during the disease. Small fibre neuropathy (SFN) is increasingly recognized in sarcoidosis. There are no specific approved therapies to treat pain and/or paraesthesia associated with SFN. GCs and conventional immunosuppressants often have little effect. In a retrospective analysis of 115 severe cases with 
SFN, an improvement in symptoms was seen in $75 \%$ of patients treated with intravenous immunogammaglobulin $(2 \mathrm{mg} / \mathrm{kg}$ ideal body weight distributed over $2-5$ days) and in $67 \%$ of those treated with IFX infusions versus less than $15 \%$ in those who did not receive any therapy [82]. Most patients with SFN receive symptomatic treatment with drugs such as gabapentin, pregabalin or antidepressants [82]. Preliminary data show a promising effect of cibinetide (ARA290), an 11-amino-acid peptide erythropoietin receptor derivative that stimulates fibre repair and is administered subcutaneously $[83,84]$. Fatigue is another common symptom of sarcoidosis. The relationship between SFN and fatigue is not clear. The treatment of sarcoidosis-associated fatigue is challenging [85]. GCs may offer benefits in newly diagnosed, symptomatic, untreated patients, but in those already treated and clinically stabilized, an increase in daily dose of GCs and/or addition of other drugs may often not be useful. Some small trials with stimulants have found them well tolerated and effective [85]. Apart from these pharmacological approaches, respiratory rehabilitation programmes, even in patients with stage 3 and 4 pulmonary sarcoidosis, have improved exercise capacity and quality-of-life scores and have been proven safe $[86,87]$.

The treatment of cardiac sarcoidosis requires particular attention, as it may manifest in very severe forms or even as sudden death. However, the fact that mortality due to cardiac sarcoidosis is mainly observed in untreated patients suggests that treatment may be successful [88]. Beyond pharmacological treatment, a permanent pacemaker is promptly recommended in cases of bradycardia, symptomatic second- or third-degree atrioventricular block, heart failure or ventricular arrhythmia. An implantable cardioverter defibrillator is added in cases of left ventricular ejection fraction less than $35 \%$ or from 36 to $49 \%$ with late gadolinium enhancement cardiac magnetic resonance evidence of myocardial scars, complete atrioventricular block, sustained ventricular tachycardia or ventricular fibrillation during electrophysiological testing and/or unexplained syncope or near-syncope felt to be arrhythmic in aetiology despite optimal medical therapy $[88,89]$. Due to the risk of infection, immunosuppression should ideally be started after the wound for device implantation has healed or at least reduced to the lowest possible maintenance dose [88]. Standard-dose GCs are the pharmacological treatment of first choice for CS. Available data suggest that early introduction of GCs can maintain left ventricular ejection fraction in patients with normal function and improve it in those with mild to moderate dysfunction at diagnosis, while contrasting results are reported in cases of severe failure [90]. A Japanese study failed to find any difference between an initial high dose of $>40 \mathrm{mg}$ /day and a lower dose of $<30 \mathrm{mg}$ [91]. GC-sparing (or adjunctive) treatments include MTX [92], AZA [93], MMF [89] and cyclophosphamide [94]. Anti-TNFs may be effective in cardiomyopathy of sarcoidosis [95], although caution is required as they can lower cardiac output. Relapses are common after reducing or discontinuing GCs $[91,96]$. Many experts start treatment of CS patients with a combination of GC and other immunosuppressants, as this may be associated with a reduced risk of relapse and disease progression, compared to GC alone [96]. An ongoing randomized controlled trial, known as CHASM, is comparing treatment of cardiac sarcoidosis with prednisone $0.5 \mathrm{mg} / \mathrm{kg} /$ day (max $30 \mathrm{mg}$ ) for 6 months versus prednisolone $20 \mathrm{mg} /$ day for 1 month, then $10 \mathrm{mg} /$ day for 1 month and then $5 \mathrm{mg} /$ day for another month plus MTX 15-20 mg once weekly for 6 months; the first endpoint was the effect on the cardiac positron emission tomography (PET)/computed tomography (CT) summed perfusion rest score [97]. Antiarrhythmic therapies have not been studied systematically, but amiodarone or sotalol can be useful in patients with ventricular arrhythmia refractory to immunosuppressants [88]. Catheter ablation can be useful in patients with ventricular arrhythmia refractory to immunosuppression and anti-arrhythmic agents, and those who do not tolerate these drugs, even if relapses are common [98]. The Heart Rhythm Society (HRS) consensus recommends management of atrial fibrillation with anticoagulants due to an increased risk of 
thromboembolism [88]. Heart transplant, apparently without extra complications, may be considered when all other therapies have failed.

\section{MANAGEMENT OF COMPLICATIONS AND COMORBIDITIES RELATED TO SARCOIDOSIS}

Some forms of lung sarcoidosis progress towards diffuse fibrosis. Pirfenidone and nintedanib are anti-fibrotic drugs currently used in idiopathic pulmonary fibrosis (IPF). Although the pathogenesis and the clinical course of fibrosis in pulmonary sarcoidosis seem to differ from that of IPF, these drugs could be promising to blunt the progression of fibrosing forms. However, nintedanib is currently the only approved treatment for pulmonary fibrosis associated with interstitial lung disease other than IPF. The INBUILD study showed that nintedanib is effective in reducing $\mathrm{FVC}$ decline even in patients with lung fibrosis due to sarcoidosis [99]. Lung transplant remains an option in patients with end-stage pulmonary sarcoidosis not helped by medical therapy. Lung transplant candidates necessarily undergo assessment of other organ involvement. Patients with mycetoma and bronchiectasis usually require bilateral lung transplant with aggressive antimicrobial therapy in the perioperative period. Long-term outcomes after lung transplant are similar to those of other indications, although short-term results may be slightly worse [100]. Increased risk of infections, sometimes with opportunistic microorganisms, has been observed in sarcoidosis, although severe forms are relatively uncommon [101]. This could be related to immunosuppressant therapy and the disease itself. Fibrocystic forms with bronchiectasis may be the most predisposed to infections [101]. The treatment of sarcoidosisrelated bronchiectasis is similar to that of other forms of bronchiectasis. Haemoptysis is relatively frequent, often associated with mycetoma and usually treated with embolization. Pulmonary aspergillosis is a severe complication and a marker of advanced lung disease [102].
Prophylaxis for Pneumocystis jirovecii pneumonia with trimethoprim/sulfamethoxazole 160/800 three times a week is usually advised for patients with sarcoidosis on more than $10 \mathrm{mg} /$ day prednisone (or its equivalent), or $\geq 0.4 \mathrm{mg} / \mathrm{kg} /$ week MTX, or $\geq 3 \mathrm{mg} / \mathrm{kg} /$ day AZA or biologics for at least several weeks $[15,16,18,19]$.

GCs and immunosuppressants are often not effective for treating sarcoidosis-associated pulmonary hypertension (SAPH), a severe complication of sarcoidosis. Several drugs are currently used for treatment of pulmonary hypertension; some of these drugs have also been used in SAPH. In an open-label study of $21 \mathrm{SAPH}$ patients, ambrisentan did not lead to improvement [103]. In another 12-month randomized, double-blind study of 17 sarcoidosis patients refractory to standard treatment, bosentan did not provide any useful result [104]. In a 16-week, double-blind, placebo-controlled trial, treatment of 35 SAPH patients with bosentan did not increase 6MWD, but improved pulmonary haemodynamics [105]. In a 24-week open-label trial, subjects with SAPH received $20 \mathrm{mg} /$ day tadalafil for the first 4 weeks and then $40 \mathrm{mg} /$ day for the subsequent 20 weeks, without any improvement in 6MWD or quality of life [106] (138). Another study found that treatment with sildenafil was associated with improved haemodynamics but not 6MWD [107]. In a 16-week open-label trial, patients on inhaled iloprost showed haemodynamic improvements [108]. Data from the French Registry indicate that 97 out of 126 patients with severe SAPH on pulmonary arterial hypertension-targeted therapy (40 also receiving background immunosuppressants) showed improvement in pulmonary haemodynamics but little or no improvement in exercise capacity [109]. Overall, these results suggest that specific treatment of pulmonary artery hypertension (endothelin receptor antagonists, phosphodiesterase-5 inhibitors, prostanoids and riociguat) may be applicable to SAPH, improving haemodynamics, but whether this translates into sustained advantages for life expectancy and patient-related outcomes is unclear.

Overall, many comorbidities, such as cardiovascular, thromboembolic and autoimmune 
disorders, sleep-related respiratory disease, diabetes, osteoporosis and malignancy, are more prevalent in sarcoidosis patients than in the healthy population [110]. When required, the same therapies as in the general population are recommended for comorbidities, except osteoporosis. Conventional administration of calcium supplements and vitamin $\mathrm{D}$ is not recommended for sarcoidosis patients, as it increases the risk of hypercalcaemia. Up to a third of sarcoidosis patients have elevated levels of 1,25-dihydroxyvitamin $\mathrm{D}$, produced by sarcoid granuloma cells. This excess leads to increased gut absorption of calcium, hypercalciuria (> $300 \mathrm{mg} /$ day in $20-50 \%$ of cases) and hypercalcaemia (5-10\% of cases). When hypercalciuria overwhelms kidney capacity of reabsorption, it may lead to nephrolithiasis and renal failure. Calcium and vitamin D should therefore be withheld in sarcoidosis patients, who should also avoid excessive sun exposure and dairy intake, unless low levels of calcitriol are demonstrated. Dietary calcium and vitamin $\mathrm{D}$ restrictions and increased fluid intake are often sufficient to normalize calcium homeostasis. If necessary, hypercalcaemia and hypercalciuria usually respond to GCs and sodium phytate. Failing GCs, ketoconazole or hydroxychloroquine are effective alternatives. Sarcoidosis patients with evidence of osteopenia and/or osteoporosis should also be treated with bisphosphonates [111].

\section{CONCLUSION}

Pulmonologists often play a key role in the management of sarcoidosis, because the lungs are by far the most commonly affected organ. However, a multidisciplinary approach is suggested to achieve the best outcome, as extrapulmonary organs are often involved.

When systemic treatment is recommended for sarcoidosis, oral GCs are the option of first choice. GCs are usually effective in treating granulomatous inflammation. The dose and duration of GC treatment should be chosen on a case-by-case basis, bearing in mind the high risk of relapses during tapering and the fact that long-term treatment periods are often required.
When GCs are started, there is a $>50 \%$ chance of requiring long-term therapy. Nevertheless, a long-term maintenance dose of more than $10 \mathrm{mg} /$ day prednisone is not advised and suggests introduction of GC-sparing drugs. The need for second- or third-choice drugs usually suggests referral to a specialist centre with experience in their use. MTX is the preferred second-choice drug in sarcoidosis treatment. It is a GC-sparing agent or is used when GCs alone are not effective; AZA is the first alternative in patients with liver disease, a previous history of liver toxicity or advanced kidney disease. Full benefit from the second-choice drug takes up to 6 months. If patient condition worsens in this period or toxic effects develop, the clinician should introduce a third-choice therapeutic option. IFX is the main preferred third-line option, perhaps except in cases of eye sarcoidosis. Of the second- and third-choice drugs for management of sarcoidosis, only MTX and IFX have been investigated in double-blind placebo-controlled randomized trials. Failure of these treatments should raise concerns about the possibility of non-adherence, superimposed complications or incorrect diagnosis. Note that treatment of the most severe lung complications involves therapies other than GCs, i.e. vasodilators for $\mathrm{SAPH}$, anti-fibrotics for fibrosis, antibiotics for infective complications. The treatment of sarcoidosis-associated fatigue and SFN are often challenging, and traditional treatments do not always offer benefits; their effective management is sometimes an unmet need.

The one-size-fits-all approach is not ideal for sarcoidosis. As knowledge increases, personalization of therapy (and hopefully more effective and safer treatment) will be an aim. One example of personalization is the case of AZA, where individual genetics (pharmacogenomics) are used to guide the treatment prescribed.

\section{ACKNOWLEDGEMENTS}

We would like to acknowledge Helen Hampt, who contributed to language editing, and other collaborators who helped to collect studies. 
Funding. No funding or sponsorship was received for this study or for publication of this article.

Authorship. All the authors meet the International Committee of Medical Journal Editors (ICMJE) criteria for authorship of this article, take responsibility for the integrity of the work as a whole, and approve publication of this version.

Authorship contributions. All authors contributed equally to the final paper, conceiving the design, reviewing the literature retrieved and drafting the manuscript. All the authors contributed to the revision and approved the final version of the paper.

Disclosure. Andrea S. Melani, Caterina Bigliazzi, Flora Anna Cimmino, Laura Bergantini and Elena Bargagli have nothing to disclose.

Compliance with Ethics Guidelines. The present review does not contain any new studies with human participants or animals performed by any of the authors.

Open Access. This article is licensed under a Creative Commons Attribution-NonCommercial 4.0 International License, which permits any non-commercial use, sharing, adaptation, distribution and reproduction in any medium or format, as long as you give appropriate credit to the original author(s) and the source, provide a link to the Creative Commons licence, and indicate if changes were made. The images or other third party material in this article are included in the article's Creative Commons licence, unless indicated otherwise in a credit line to the material. If material is not included in the article's Creative Commons licence and your intended use is not permitted by statutory regulation or exceeds the permitted use, you will need to obtain permission directly from the copyright holder. To view a copy of this licence, visit http://creativecommons.org/licenses/by$\mathrm{nc} / 4.0 /$.

\section{REFERENCES}

1. Judson MA, Chaudhry H, Louis A, Lee K, Yucel R. The effect of corticosteroids on quality of life in a sarcoidosis clinic: the results of a propensity analysis. Respir Med. 2015;109(4):526-31.

2. Thillai M, Chang W, Chaudhuri N, et al. Sarcoidosis in the UK: insights from British Thoracic Society registry data. BMJ Open Respir Res. 2019;6(1): e000357. https://doi.org/10.1136/bmjresp-2018000357.

3. Milman N, Graudal N, Grode G, et al. No effect of high-dose inhaled steroids in pulmonary sarcoidosis: a double-blind, placebo-controlled study. J Intern Med. 1994;236:285-90.

4. Pietinalho A, Lindholm A, Haahtela T, Tukiainen P, Selroos O. Inhaled budesonide for treatment of pulmonary sarcoidosis: results of a double-blind, placebo-controlled, multicentre study. Eur Respir J. 1996;9:406s.

5. Baughman RP, Iannuzzi MC, Lower EE, et al. Use of fluticasone in acute symptomatic pulmonary sarcoidosis. Sarcoidosis Vasc Diffuse Lung Dis. 2002;19:198-204.

6. du Bois RM, Greenhalgh PM, Southcott AM, et al. Randomized trial of inhaled fluticasone propionate in chronic stable pulmonary sarcoidosis: a pilot study. Eur Respir J. 1999;13:1345-50.

7. Khan NA, Donatelli CV, Tonelli AR, et al. Toxicity risk from glucocorticoids in sarcoidosis patients. Respir Med. 2017;132:9-14.

8. James DG, Trowell J, Sharma OPCLS, et al. Treatment of sarcoidosis. Report of a controlled therapeutic trial. Lancet. 1967;2:526.

9. Gibson GJ, Prescott RJ, Muers MF, et al. British Thoracic Society Sarcoidosis study: effects of long term corticosteroid treatment. Thorax. 1996;51: $238-47$.

10. Sones M, Israel HL, Dratman MBFJ. Effect of cortisone in sarcoidosis. N Engl J Med. 1951;244:209-13.

11. Rahaghi FF, Baughman RP, Saketkoo LA, et al. Delphi consensus recommendations for a treatment algorithm in pulmonary sarcoidosis. Eur Respir Rev. 2020;29(155):pii:190146. https://doi.org/10.1183/ 16000617.0146-2019.

12. Thillai M, Atkins CP, Crawshaw A, et al. BTS clinical statement on pulmonary sarcoidosis. Thorax. 2020;76(1):4-20. https://doi.org/10.1136/thoraxjnl2019-214348 (PMID: 33268456). 
13. Broos CE, Poell LHC, Looman CWN, et al. No evidence found for an association between prednisone dose and FVC change in newly-treated pulmonary sarcoidosis. Respir Med. 2018;138S:S31-7.

14. Drent M, Proesmans VLJ, Elfferich MDP, et al. Ranking self-reported gastrointestinal side effects of pharmacotherapy in sarcoidosis. Lung. 2020;198(2): 395-403. https://doi.org/10.1007/s00408-02000323-8 (PMID: 31960165).

15. Pande A, Culver DA. Knowing when to use steroids, immunosuppressants or biologics for the treatment of sarcoidosis. Expert Rev Respir Med. 2020;14(3): 285-98.

16. Baughman RP, Meyer KC, Nathanson I, et al. Executive summary: monitoring of nonsteroidal immunosuppressive drugs in patients with lung disease and lung transplant recipients: American College of Chest Physicians evidence-based clinical practice guidelines. Chest. 2012;142(5):1284-8.

17. Götestam Skorpen C, Hoeltzenbein M, et al. The EULAR points to consider for use of antirheumatic drugs before pregnancy, and during pregnancy and lactation. Ann Rheum Dis. 2016;75(5):795-810.

18. Ledingham J, Gullick N, Irving $\mathrm{K}$, et al. BSR and BHPR guideline for the prescription and monitoring of non-biologic disease-modifying anti-rheumatic drugs. Rheumatology. 2017;56(6):865-8.

19. Syed H, Ascoli C, Linssen CF, et al. Infection prevention in sarcoidosis: proposal for vaccination and prophylactic therapy. Sarcoidosis Vasc Diffuse Lung Dis. 2020;37(2):87-98. https://doi.org/10.36141/ svdld.v37i2.9599 (PMID: 33093774).

20. Baughman RP, Winget DB, Lower EE. Methotrexate is steroid sparing in acute sarcoidosis: results of a double blind, randomized trial. Sarcoidosis Vasc Diffuse Lung Dis. 2000;17:60-6.

21. Cronstein BN, Aune TM. Methotrexate and its mechanisms of action in inflammatory arthritis. Nat Rev Rheumatol. 2020;16(3):145-54. https://doi. org/10.1038/s41584-020-0373-9.

22. Jones G, Sebba A, Gu J, et al. Comparison of tocilizumab monotherapy versus methotrexate monotherapy in patients with moderate to severe rheumatoid arthritis: the AMBITION study. Ann Rheum Dis. 2010;69(1):88-96.

23. Grosen A, Kelsen J, Hvas CL, Bellaguarda E, Hanauer SB. The influence of methotrexate treatment on male fertility and pregnancy outcome after paternal exposure. Inflamm Bowel Dis. 2017;23(4):561-9.

24. Schaeffeler E, Jaeger SU, Klumpp V, et al. Impact of NUDT15 genetics on severe thiopurine-related hematotoxicity in patients with European ancestry. Genet Med. 2019;21(9):2145-50. https://doi.org/10. 1038/s41436-019-0448-7 (PMID: 30728528).

25. Vorselaars ADM, Wuyts WA, Vorselarrs VMM, et al. Methotrexate vs. azathioprine in second-line therapy of sarcoidosis. Chest. 2013;144:805-12.

26. Sahoo DH, Bandyopadhyay D, Xu M, et al. Effectiveness and safety of leflunomide for pulmonary and extrapulmonary sarcoidosis. Eur Respir J. 2011;38:1145-50.

27. Broen JCA, van Laar JM. Mycophenolate mofetil, azathioprine and tacrolimus: mechanisms in rheumatology. Nat Rev Rheumatol. 2020;16(3): 167-78. https://doi.org/10.1038/s41584-020-03748.

28. Hamzeh N, Voeleker A, Forssen A, et al. Efficacy of mycophenolate mofetil in sarcoidosis. Respir Med. 2014;108:1663-9.

29. Schrezenmeier E, Dörner T. Mechanisms of action of hydroxychloroquine and chloroquine: implications for rheumatology. Nat Rev Rheumatol. 2020;16(3):155-66. https://doi.org/10.1038/ s41584-020-0372-x.

30. Cohen Aubart F, Abbara S, Maisonobe T, et al. Symptomatic muscular sarcoidosis: Lessons from a nationwide multicenter study. Neurol Neuroimmunol Neuroinflamm. 2018;5(3):e452.

31. Baltzan M, Mehta S, Kirkham TH, Cosio MG. Randomized trial of prolonged chloroquine therapy in advanced pulmonary sarcoidosis. Am J Respir Crit Care Med. 1999;160(1):192-7.

32. Marmor MF. The 2016 American Academy of Ophthalmology recommendations for hydroxychloroquine dosing give accurate advice for all patients. Ophthalmol Retina. 2019;3(10):807-8.

33. Lower EE, Sturdivant M, Grate L, Baughman RP. Use of third-line therapies in advanced sarcoidosis. Clin Exp Rheumatol. 2020;38(5):834-40.

34. Gelfand JM, Bradshaw MJ, Stern BJ, et al. Infliximab for the treatment of CNS sarcoidosis: A multi-institutional series. Neurology. 2017;89(20):2092-100.

35. Jamilloux Y, Cohen-Aubart F, Chapelon-Abric C, for the Groupe Sarcoïdose Francophone, et al. Efficacy and safety of tumor necrosis factor antagonists in refractory sarcoidosis: A multicenter study of 132 patients. Semin Arthritis Rheum. 2017;47(2): 288-94.

36. Baughman RP, Drent M, Kavuru M, et al. Infliximab therapy in patients with chronic sarcoidosis and 
pulmonary involvement. Am J Respir Crit Care Med. 2006;174:795-802.

37. Rossman MD, Newman LS, Baughman RP, et al. A double-blind, randomized, placebo-controlled trial of infliximab in patients with active pulmonary sarcoidosis. Sarcoidosis Vasc Diffuse Lung Dis. 2006;23:201-8.

38. Wijnen PA, Cremers JP, Nelemans PJ, et al. Association of the TNF- $\alpha$ G-308A polymorphism with TNF-inhibitor response in sarcoidosis. Eur Respir J. 2014;43:1730-9.

39. Schimmelpennink MC, Vorselaars ADM, van Beek FT, et al. Efficacy and safety of infliximab biosimilar Inflectra $_{\circledast}$ in severe sarcoidosis. Respir Med. 2018;138S:S7-13.

40. Crommelin HA, van der Burg LM, Vorselaars AD, et al. Efficacy of adalimumab in sarcoidosis patients who developed intolerance to infliximab. Respir Med. 2016;115:72-7.

41. Quistrebert J, Hässler S, Bachelet D, ABIRISK Consortium, et al. Incidence and risk factors for adalimumab and infliximab anti-drug antibodies in rheumatoid arthritis: A European retrospective multicohort analysis. Semin Arthritis Rheum. 2019;48(6):967-75.

42. Sweiss NJ, Lower EE, Mirsaeidi M, Dudek S, Garcia Joe GN, Perkins D, Finn PW, Baughman RP. Rituximab in the treatment of refractory pulmonary sarcoidosis. Eur Respir J. 2014;43:1525-8.

43. Baughman RP, Sweiss N, Keijsers R, et al. Repository corticotropin for Chronic Pulmonary Sarcoidosis. Lung. 2017;195(3):313-22.

44. Rahaghi FF, Sweiss NJ, Saketkoo LA, et al. Management of repository corticotrophin injection therapy for pulmonary sarcoidosis: a Delphi study. Eur Respir Rev. 2020;29(155):pii:190147. https://doi. org/10.1183/16000617.0147-2019.

45. Drake WP, Richmond BW, Oswald-Richter K, et al. Effects of broad-spectrum antimycobacterial therapy on chronic pulmonary sarcoidosis. Sarcoidosis Vasc Diffuse Lung Dis. 2013;30(3):201-11.

46. Drake WP, Oswald-Richter K, Richmond BW, et al. Oral antimycobacterial therapy in chronic cutaneous sarcoidosis. JAMA Dermatol. 2013;149(9): 1040-9.

47. Yamaguchi T, Yamaguchi Y, Suzuki M, Kawano C, Yamada K. Doxycycline therapy for sarcoidosis. J Jpn Soc Sarcoidosis Other Granulomatous Dis. 2014;34:31-3.
48. Frye BC, Rump IC, Uhlmann A, et al. Safety and efficacy of abatacept in patients with treatment-resistant SARCoidosis (ABASARC) - protocol for a multi-centre, single-arm phase IIa trial. Contemp Clin Trials Commun. 2020;29(19):100575. https:// doi.org/10.1016/j.conctc.2020.100575.

49. Baughman RP, Judson MA, Ingledue R, et al. Efficacy and safety of apremilast in chronic cutaneous sarcoidosis. Arch Dermatol. 2012;148(2):262-4.

50. Fontana JR, Moss J, Stylianou M, et al. Atorvastatin treatment for pulmonary sarcoidosis, a randomized, double-blind, placebo-controlled clinical trial. Am J Respir Crit Care Med. 2017;195:A4755.

51. Wyser CP, van Schalkwyk EM, Alheit B, et al. Treatment of progressive pulmonary sarcoidosis with cyclosporine A. A randomized controlled trial. Am J Respir Crit Care Med. 1997;156(5):1371-6.

52. Kaçmaz RO, Kempen JH, Newcomb C, et al. Cyclosporine for ocular inflammatory diseases. Ophthalmology. 2010;117(3):576-84.

53. Wroblewski K, Sen HN, Yeh S, et al. Long-term daclizumab therapy for the treatment of noninfectious ocular inflammatory disease. Can J Ophthalmol. 2011;46(4):322-8.

54. Utz JP, Limper AH, Kalra S, et al. Etanercept for the treatment of stage II and III progressive pulmonary sarcoidosis. Chest. 2003;124(1):177-85.

55. Baughman RP, Lower EE, Bradley DA, Raymond LA, Kaufman A. Etanercept for refractory ocular sarcoidosis. Results of a double-blind study. Chest. 2005;128:1062-7.

56. Judson MA, Baughman RP, Costabel U, et al. Safety and efficacy of ustekinumab or golimumab in patients with chronic sarcoidosis. Eur Respir J. 2014;44(5):1296-307.

57. Sahu KK, Varma SC. Lenalidomide in nonmalignant disorders: a new ray of hope for refractory sarcoidosis. Chest. 2015;148(6):e188-9.

58. Baughman RP, Culver DA, Jankovi V, Fischkoff S, Brockway G, Lower EE. Placenta-derived mesenchymal-like cells (PDA-001) as therapy for chronic pulmonary sarcoidosis: a phase 1 study. Sarcoidosis Vasc Diffuse Lung Dis. 2015;32(2): 106-14.

59. Julian MW, Shao G, Schlesinger LS, et al. Nicotine treatment improves toll-like receptor 2 and toll-like receptor 9 responsiveness in active pulmonary sarcoidosis. Chest. 2013;143(2):461-70. 
60. Park MK, Fontana JR, Babaali H, et al. Steroid sparing effects of pentoxifylline in pulmonary sarcoidosis. Sarcoidosis. 2009;26(2):121-31.

61. Baughman RP, Birring S, Judson MA, et al. A double blind, placebo controlled study of roflumilast to prevent acute events in fibrotic sarcoidosis. Am J Respir Crit Care Med. 2017;195:A4752.

62. Baughman RP, Judson MA, Teirstein AS, et al. Thalidomide for chronic sarcoidosis. Chest. 2002;122:227-32.

63. Fazzi P, Manni E, Cristofani R, et al. Thalidomide for improving cutaneous and pulmonary sarcoidosis in patients resistant or with contraindications to corticosteroids. Biomed Pharmacother. 2012;66(4): 300-7.

64. Droitcout C, Rybojad M, Porcher R, et al. A randomized, investigator-masked, double-blind, placebo-controlled trial on thalidomide in severe cutaneous sarcoidosis. Chest. 2014;146(4):1046-54.

65. Sharp M, Donnelly SC, Moller DR. Tocilizumab in sarcoidosis patients failing steroid sparing therapies and anti-TNF agents. Respir Med. 2019;1:pii: 100004. https://doi.org/10.1016/j.yrmex.2019. 100004.

66. Rotemberg C, Besnard V, Brillet PY, Giraudier S, Nunes H, Valeyre D. Dramatic response of refractory sarcoidosis under roxulitinib in a patient with associated JAK2-mutated polycythemia. Eur Respir J. 2018;52(6):1801482.

67. Wei JJ, Lisa R, Kallenbach LR, et al. Resolution of cutaneous sarcoidosis after Janus kinase inhibitor therapy for concomitant polycythemia vera. JAAD Case Rep. 2019;5(4):360-1. https://doi.org/10.1016/ j.jdcr.2019.02.006 (PMC6453827).

68. Damsky W, Young BD, Sloan B, Miller EJ, Obando JA, King B. Treatment of multiorgan sarcoidosis with tofacitinib. ACR Open Rheumatol. 2020;2(2): 106-9.

69. Damsky W, Thakral D, McGeary MK, Leventhal J, Galan A, King B. Janus kinase inhibition induces disease remission in cutaneous sarcoidosis and granuloma annulare. J Am Acad Dermatol. 2020;82(3):612-21.

70. Prasse A, Zissel G, Lützen N, et al. Inhaled vasoactive intestinal peptide exerts immunoregulatory effects in sarcoidosis. Am J Respir Crit Care Med. 2010;182:540-54.

71. Matsou A, Tsaousis KT. Management of chronic ocular sarcoidosis: challenges and solutions. Clin Ophthalmol. 2018;12:519-32.
72. Kempen JH, Altaweel MM, Holbrook JT, Sugar EA, Thorne JE, Jabs DA, for the Writing Committee for the Multicenter Uveitis Steroid Treatment (MUST) Trial and Follow-up Study Research Group. Association between long-lasting intravitreous fluocinolone acetonide implant vs systemic antiinflammatory therapy and visual acuity at 7 years among patients with intermediate, posterior, or panuveitis. JAMA. 2017;317(19):1993-2005.

73. Dick AD, Rosenbaum JT, Al-Dhibi HA, on behalf of the Fundamentals of Care for Uveitis International Consensus Group, et al. Guidance on noncorticosteroid systemic immunomodulatory therapy in noninfectious uveitis: Fundamentals Of Care for UveitiS (FOCUS) initiative. Ophthalmology. 2018;125(5):757-73.

74. Browne EN, Rathinam SR, Kanakath A, et al. A Bayesian analysis of a randomized clinical trial comparing antimetabolite therapies for non-infectious uveitis. Ophthalmic Epidemiol. 2017;24(1): $63-70$.

75. Vallet H, Seve P, Biard L, Baptiste Fraison J, on behalf of the French Uveitis Network, et al. Infliximab versus adalimumab in the treatment of refractory inflammatory uveitis: a multicenter study from the French Uveitis Network. Arthritis Rheumatol. 2016;68(6):1522-30.

76. Jaffe GJ, Dick AD, Brézin AP, et al. Adalimumab in patients with active noninfectious uveitis. N Engl J Med. 2016;375(10):932-4.

77. Nguyen QD, Merrill PT, Jaffe GJ, et al. Adalimumab for prevention of uveitic flare in patients with inactive non-infectious uveitis controlled by corticosteroids (VISUAL II): a multicentre, doublemasked, randomised, placebo-controlled phase 3 trial. Lancet. 2016;388(10050):1183-92.

78. Al-Kofahi K, Korsten P, Ascoli C, Virupannavar S, Mirsaeidi M, Chang I, Qaqish N, Saketkoo LA, Baughman RP, Sweiss NJ. Management of extrapulmonary sarcoidosis: challenges and solutions. Ther Clin Risk Manag. 2016;12:1623-34.

79. Bitoun S, Bouvry D, Borie R, Mahevas M, Sacre K, Haroche J, Psimaras D, Pottier C, Mathian A, Hie M, Boutin DL, Papo T, Godeau B, Valeyre D, Nunes H, Amoura Z, Cohen AF. Treatment of neurosarcoidosis: a comparative study of methotrexate and mycophenolate mofetil. Neurology. 2016;87(24): 2517-21.

80. Sodhi M, Pearson K, White ES, Culver DA. Infliximab therapy rescues cyclophosphamide failure in severe central nervous system sarcoidosis. Respir Med. 2009;103(2):268-73. 
81. Cohen Aubart F, Bouvry D, et al. Long-term outcomes of refractory neurosarcoidosis treated with infliximab. J Neurol. 2017;264(5):891-7.

82. Tavee JO, Karwa K, Ahmed Z, Thompson N, Parambil J, Culver DA. Sarcoidosis-associated small fibre neuropathy in a large cohort: Clinical aspects and response to IVIG and anti-TNF alpha treatment. Respir Med. 2017;126:135-8.

83. Heij L, Niesters M, Swartjes M, et al. Safety and efficacy of ArA 290 in sarcoidosis patients with symptoms of small fibre neuropathy: a randomized, double-blind pilot study. Mol Med. 2012;18: 1430-6.

84. Culver DA, Dahan A, Bajorunas D, Jeziorska M, van Velzen M, Aarts LPHJ, Tavee J, Tannemaat MR, Dunne AN, Kirk RI, Petropoulos IN, Cerami A, Malik RA, Brines M. Cibinetide improves corneal nerve fiber abundance in patients with sarcoidosis-associated small nerve fiber loss and neuropathic pain. Invest Ophthalmol Vis Sci. 2017;58(6):BIO52-60.

85. Vis R, van de Garde EMW, Grutters JC, Korenromp IHE. The effects of pharmacological interventions on quality of life and fatigue in sarcoidosis: a systematic review. Eur Respir Rev. 2020;29(155):pii: 190057. https://doi.org/10.1183/16000617.00572019.

86. Grongstad A, Spruit MA, Oldervoll LM, Vøllestad NK, Edvardsen A. Pulmonary rehabilitation in patients with pulmonary sarcoidosis: impact on exercise capacity and fatigue. Respiration. 2020;4: 1-9. https://doi.org/10.1159/000506295.

87. Kullberg S, Rivera NV, Eriksson MJ, Grunewald J, Eklund A. High-intensity resistance training in newly diagnosed sarcoidosis-an exploratory study of effects on lung function, muscle strength, fatigue, dyspnea, health-related quality of life and lung immune cells. Eur Clin Respir J. 2020;7(1):1730137. https://doi.org/10.1080/20018525.2020.1730137.

88. Birnie DH, Sauer WH, Bogun F, et al. on behalf of the HRS expert consensus statement on the diagnosis and management of arrhythmias associated with cardiac sarcoidosis. Heart Rhythm. 2014;11(7): 1305-12.

89. Zhou Y, Lower EE, Li HP, Costea A, Attari M, Baughman RP. Cardiac Sarcoidosis: The impact of age and implanted devices on survival. Chest. 2017;151(1):139-48.

90. Padala SK, Peaslee S, Sidhu MS, Steckman DA, Judson MA. Impact of early initiation of corticosteroid therapy on cardiac function and rhythm in patients with cardiac sarcoidosis. Int J Cardiol. 2017;227: $565-70$.
91. Yazaki $Y$, Isobe M, Hiroe $M$, on behalf of the Central Japan Heart Study Group, et al. Prognostic determinants of long-term survival in Japanese patients with cardiac sarcoidosis treated with prednisone. Am J Cardiol. 2001;88(9):1006-10.

92. Nagai S, Yokomatsu T, Tanizawa K, et al. Treatment with methotrexate and low-dose corticosteroids in sarcoidosis patients with cardiac lesions. Intern Med. 2014;53:2761.

93. Müller-Quernheim J, Kienast $\mathrm{K}$, Held $\mathrm{M}$, et al. Treatment of chronic sarcoidosis with an azathioprine/prednisolone regimen. Eur Respir J. 1999;14: 1117-22.

94. Demeter SL. Myocardial sarcoidosis unresponsive to steroids. Treatment with cyclophosphamide. Chest. 1988;94:202-3.

95. Harper LJ, McCarthy M, Ribeiro Neto ML, et al. Infliximab for refractory cardiac sarcoidosis. Am J Cardiol. 2019;124(10):1630-5.

96. Ballul T, Borie R, Creastani B, et al. Treatment of cardiac sarcoidosis: A comparative study of steroids and steroids plus immunosuppressive drugs. Int J Cardiol. 2019;276:208-11.

97. Birnie D, Beanlands RSB, Nery P, et al. Cardiac Sarcoidosis multi-centre randomized controlled trial (CHASM CS- RCT). Am Heart J. 2020;220:246-52. https://doi.org/10.1016/j.ahj.2019.10.003 (PMID: 31911261).

98. Papageorgiou N, Providência R, Bronis $\mathrm{K}$, et al. Catheter ablation for ventricular tachycardia in patients with cardiac sarcoidosis: a systematic review. Europace. 2018;20(4):682-91.

99. Wells AU, Flaherty KR, Brown KK, for the INBUILD trial investigators, et al. Nintedanib in patients with progressive fibrosing interstitial lung diseases-subgroup analyses by interstitial lung disease diagnosis in the INBUILD trial: a randomised, double-blind, placebo-controlled, parallel-group trial. Lancet Respir Med. 2020. https://doi.org/10.1016/S22132600(20)30036-9.

100. Taimeh Z, Hetrz MI, Shumway S, Pritzker M. Lung transplantation for pulmonary sarcoidosis. Twentyfive years of experience in the USA. Thorax. 2016;71:378-9.

101. Duréault A, Chapelon C, Biard L, et al. Severe infections in sarcoidosis: Incidence, predictors and long-term outcome in a cohort of 585 patients. Medicine (Baltimore). 2017;96(49):e8846.

102. Uzunhan Y, Nunes H, Jeny F, et al. Chronic pulmonary aspergillosis complicating sarcoidosis. Eur 
Respir J. 2017;49(6):pii: 1602396. https://doi.org/ 10.1183/13993003.02396-201.

103. Judson MA, Highland KB, Kwon S, et al. Ambrisentan for sarcoidosis associated pulmonary hypertension. Sarcoidosis Vasc Diffuse Lung Dis. 2011;28:139-45.

104. Hostettler KE, Baty F, Kleiner R, Junker L, Tamm M, Brutsche $\mathrm{M}$. Bosentan for patients with steroid-resistant pulmonary sarcoidosis: a randomised controlled trial. Swiss Med Wkly. 2018;148:w14677.

105. Baughman RP, Culver DA, Cordova FC, et al. Bosentan for sarcoidosis-associated pulmonary hypertension: a double-blind placebo controlled randomized trial. Chest. 2014;145(84):810-7.

106. Ford HJ, Baughman RP, Aris R, Engel P, Donohue JF. Tadalafil therapy for sarcoidosis-associated pulmonary hypertension. Pulm Circ. 2016;6(4): $557-62$.

107. Milman N, Burton CM, Iversen M, Videbaek R, Jensen CV, Carlsen J. Pulmonary hypertension in end-stage pulmonary sarcoidosis: therapeutic effect of sildenafil? J Heart Lung Transplant. 2008;27(3): 329-34.

108. Bonham CA, Oldham JM, Gomberg-Maitland M, et al. Prostacyclin and oral vasodilator therapy in sarcoidosis-associated pulmonary hypertension: a retrospective case-series. Chest. 2015;148(4): 1055-62.

109. Boucly A, Cottin V, Nunes H, et al. Management and long-term outcomes of sarcoidosis-associated pulmonary hypertension. Eur Respir J. 2017;50(4): pii: 1700465. https://doi.org/10.1183/13993003. 00465-2017.

110. Brito-Zerón P, Acar-Denizli N, Sisó-Almirall A, et al. The burden of comorbidity and complexity in sarcoidosis: impact of associated chronic diseases. Lung. 2018;196(2):239-48.

111. Baughman RP, Papanikolaou I. Current concepts regarding calcium metabolism and bone health in sarcoidosis. Curr Opin Pulm Med. 2017;23(5): 476-81. 